Research Article

\title{
Determination of the Mechanical Properties of Friction Welded Tube Yoke and Tube Joint
}

\author{
Efe Işı1k ${ }^{1,2}$ and Çiçek Özes ${ }^{3}$ \\ ${ }^{1}$ The Graduate School of Natural and Applied Sciences, Dokuz Eylül University, 35397 Izmir, Turkey \\ ${ }^{2}$ Tirsan Kardan A.Ş., 45030 Manisa, Turkey \\ ${ }^{3}$ Faculty of Engineering, Dokuz Eylül University, 35397 Izmir, Turkey
}

Correspondence should be addressed to Çiçek Özes; cicek.ozes@deu.edu.tr

Received 27 April 2016; Revised 18 June 2016; Accepted 27 June 2016

Academic Editor: Guru P. Dinda

Copyright (C) 2016 E. Işık and Ç. Özes. This is an open access article distributed under the Creative Commons Attribution License, which permits unrestricted use, distribution, and reproduction in any medium, provided the original work is properly cited.

\begin{abstract}
This paper deals with the friction welding of the tube yoke and the tube of the drive shaft used in light commercial vehicles. Tube yoke made from hot forged microalloyed steel and the tube made from cold drawn steel, with a ratio (thickness/outside diameter ratio) of less than 0.1 , were successfully welded by friction welding method. Hardness distributions on both sides of the welded joint across the welding interface were determined and the microstructure of the joint was investigated. Furthermore, joint strength was tested under tensile, static torsional, and torsional fatigue loadings. The tested data were analyzed by Weibull distribution. The maximum hardness value along the welded joint was detected as $553 \mathrm{Hvl}$. The lowest detected tensile strength of the joint was $13 \%$ less than the base materials' tensile strength. The torsional load carrying capacity of the friction welded thin walled tubular joint without any damage was obtained as $4.252,5 \mathrm{Nm}$ in $95 \%$ confidence interval. After conducting fully reversed torsional fatigue tests, the fatigue life of friction welded tubular joints was detected as $220.066,3$ cycles.
\end{abstract}

\section{Introduction}

Tubular structures are achieving extensive applications in many fields of the automotive industries, construction, and marine sectors. They are widely used in various components such as drive shafts, engine valves, pipeline, and vacuum vessels. During product assembly, the joining of these parts usually requires joining technologies, such as welding. Friction welding is one of the most commonly used methods as a solid state welding technique in both solid [1-4] and tubular structures of the similar and dissimilar materials [5-13]. Many researchers have conducted studies on friction welding of tubular structures to understand the joining mechanism during the welding process and to determine the mechanical properties of welded joints for similar and dissimilar materials.

Researchers, who studied the friction welding of tubular sections with a ratio $(t / D)$ larger than 0.1 , reported that the joining of tubular sections having similar materials could be successfully achieved $[14,15]$. The friction welding method for thin walled tubular sections with a ratio $(t / D)$ of 0.1 and less was studied by Kimura et al. [16] and Kumar and Balasubramanian [17]. Kimura et al. studied the weldability of thin walled austenitic stainless steel pipe of various thicknesses, under various friction welding conditions, and proposed that the friction welding technique is suitable for the welding of thin walled circular austenitic stainless steel pipes. Kumar and Balasubramanian showed that the SUS $304 \mathrm{HCu}$ tubes can be successfully welded using friction welding process.

Researchers reported that the mechanical and metallurgical properties of the friction welded joints of tubular sections with a ratio $(t / D)$ larger than 0.1 showed desirable characteristics for also dissimilar material combinations. Various aluminum alloys which were friction welded to steels pipes were investigated by Kawai et al. [18] and Ohkuba et al. [19]. The dissimilar friction welding of tubular Zr-based BMGs to BMGs having a pipe thickness of $1 \mathrm{~mm}$ has been studied by Shin et al. Results showed that the successful joining could be obtained for certain pairs of the material combinations through precise control of welding parameters [20]. 
TABLE 1: Chemical composition and mechanical properties of base material (\% weight).

\begin{tabular}{lcccccccc}
\hline & $\mathrm{C}$ & $\mathrm{Si}$ & $\mathrm{Mn}$ & $\mathrm{P}$ & $\mathrm{S}$ & $\mathrm{V}$ & $\mathrm{Al}$ & Tensile strength (MPa) \\
\hline Nonalloyed structural steel $^{*}[31]$ & 0.22 & 0.55 & 1.60 & 0.025 & 0.025 & - & $0.02^{* *}$ & $640^{* *}$ \\
\hline \multirow{2}{*}{ Microalloyed steel } & 0.32 & 0.15 & 1.30 & - & 0.08 & 0.02 & - & $750^{* *}$ \\
& 0.39 & 0.25 & 1.50 & 0.04 & 0.13 & 0.2 & \\
\hline
\end{tabular}

${ }^{*} \operatorname{Max},{ }^{* *} \operatorname{Min}$.

Although the friction welding method is convenient for tubular sections the joining of these having $t / D$ ratio smaller than 0.1 is rather difficult, and few studies exist on this issue.

Kimura et al's work focuses on the clarification of the joining phenomena during the friction process of friction welds of thin walled circular pipes of dissimilar combinations between aluminum alloy and austenitic stainless steel thin walled pipe. Furthermore, the authors propose that this friction welding technique is also suitable for the welding of thin walled circular pipes of dissimilar combinations [21].

In practice, welded joints of tubular structures are used to transmit the torque for light, medium, and heavy commercial vehicles. The structural durability of the welding joints against torsional loads is directly affecting the service life of the drive shaft. In this study, the tube yoke and the tube of a drive shaft, which is a mechanical part that transmits the torque used in light commercial vehicles, have been successfully friction welded. Tube yoke made from hot forged microalloyed steel and the tube made from cold drawn steel have a thickness/outside diameter ratio $(t / D=0.0543)$ of less than 0.1 . The microstructural properties of heat affected zones (HAZ) were examined and the microhardness on both sides of the welded joint across the welding interface was measured. The tensile strengths of the welding joints were determined by using samples which were extracted from the welding zone. In order to detect the structural durability of the welding zone under torsion which is directly affecting the service life, static torsion and fully reversed torsional fatigue tests were performed to the drive shaft samples.

\section{Experimental Procedure}

2.1. Materials. The tube yoke made from hot forged microalloyed steel and the tube made from welded cold drawn nonalloyed structural steel were used. In order to achieve the desired mechanical properties, tube yoke was subjected to precipitation hardening process. The chemical composition and the mechanical properties of each base material are listed in Table 1. Banded ferrite and pearlite were observed in the base metal due to high levels of plastic deformation in welded cold drawn steel tube (Figure 1). Hot forged microalloyed steel tube yoke shows a pearlite and grain boundary ferrite microstructure (Figure 2).

2.2. Method. Hot forged microalloyed tube yokes and welded cold drawn nonalloyed steel tubes were successfully welded using direct drive friction welding method. In this method, the contact of work pieces rotating and moving relative to each other under compressive forces produces heat which is required to create the bonding between the work pieces

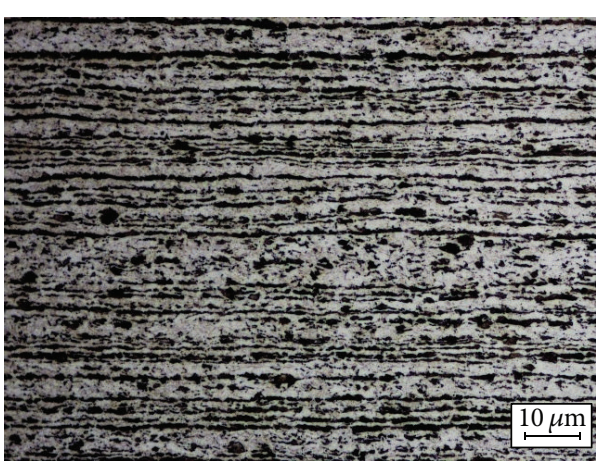

FIGURE 1: Microstructure of welded cold drawn nonalloyed structural steel tube.

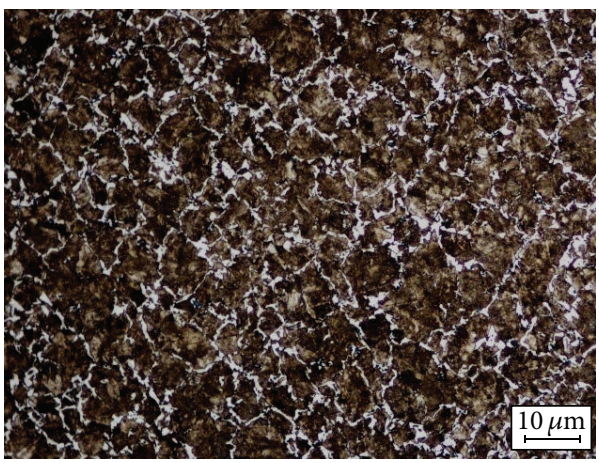

FIGURE 2: Microstructure of microalloyed steel tube yoke.

and removes excessive material from the welding joint, permanently [22]. Narrow heat affected zone (HAZ), lower production cycle time and high productivity, lower material and energy consumption, and reduced microstructural changes in the welding zone can be considered as some of the advantages of this method [22-25].

In direct drive friction welding, the most preferred process type, heat is generated at the welding zone by rotating one work piece against the other one at constant or varying speed with an axial pressure for a predetermined period of time.

Energy is continuously supplied to the mating parts until sufficient heat is generated in the welding zone [26]. As soon as the proper energy level in the welding zone is achieved, the rotating part is suddenly stopped and both parts are permanently bonded with the help of an axial force called the "upset pressure" which is nearly 10 times higher than the friction force. The flow and characteristics of some 


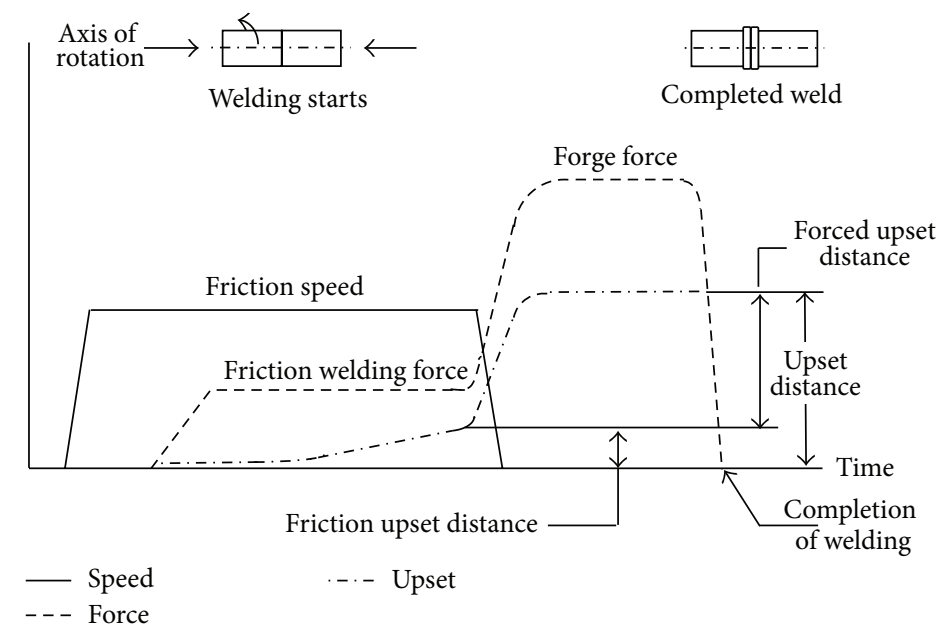

FIGURE 3: Process parameters in direct drive friction welding technique [22].

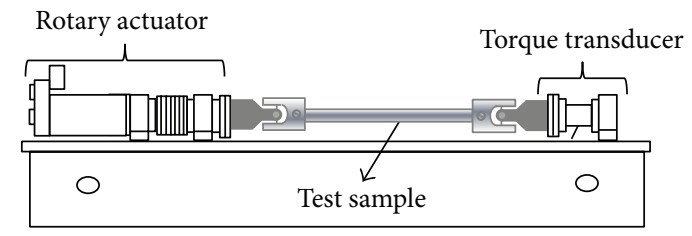

FIGURE 4: Schematic representation of the torsional test machine.

major welding parameters during the process is graphically demonstrated in Figure 3.

The friction welding process was conducted on a twin head direct drive rotary friction welding machine which has an upset force capacity of 15 ton. The welding parameters used are as follows: friction pressure rate of $15 \mathrm{MPa}$ per second, forging pressure rate of $37 \mathrm{MPa}$ per second, and rotational speed of $900 \mathrm{rpm}$. The upset distance is approximately two times of the wall thickness. 40 samples were welded with the above-mentioned process parameters under the same conditions.

The macrostructure properties in the welding interface of the welded samples were observed and the microstructure of the friction welding joints was investigated by using an optical microscope. Then, the Vickers microhardness values were measured on both sides of the welded specimens. To determine the joint strength, specimens which were extracted from the welding zone by using wire EDM technique are subjected to tensile test by using Shimadzu Autograph AGIS test machine with a capacity of 10 ton. Static torsion and torsional fatigue tests were conducted at room temperature with a horizontal single-axis torsion test machine having a maximum loading capacity of $16 \mathrm{kNm}$. Fully reversed $(R=$ $-1)$ torsional fatigue tests were also conducted. Schematic representation of the test machine is shown in Figure 4.

\section{Results and Discussion}

3.1. Macrostructural Analysis. The friction welded joint and the specimen extracted from the weld zone are presented

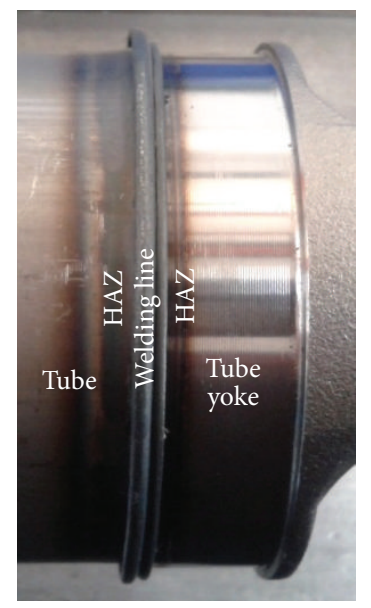

FIGURE 5: Friction welded joint.

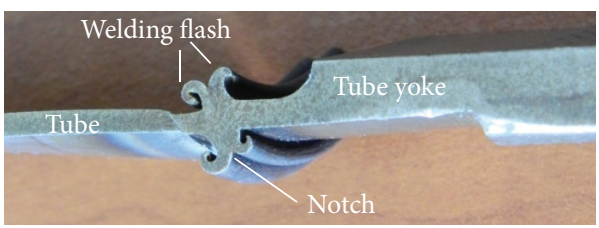

FIGURE 6: Specimen extracted from the weld zone.

in Figures 5 and 6, respectively. This type of welded joint is characterized by a narrow heat affected zone on each side of the base material and the presence of plastically deformed excessive material, which is called the welding flash, around the welding line [22].

Mostly, a symmetrical part geometry is recommended in friction welding applications. The weldments are usually between circular cross-sectioned solid bars or tubular sectioned parts. This symmetrical joint provides homogeneous heat flow through the joint during the process, eases flash 


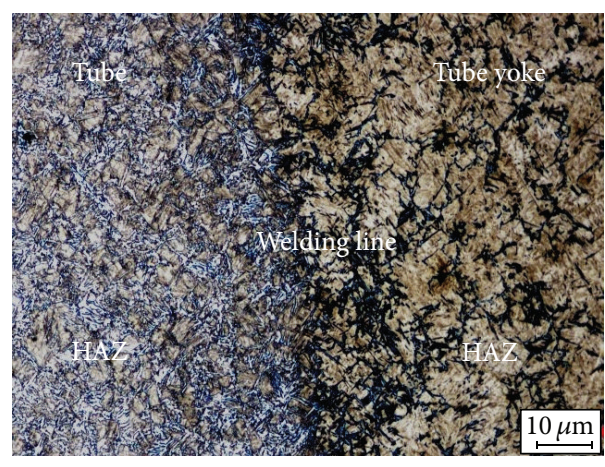

Figure 7: Microstructure of the welding zone.

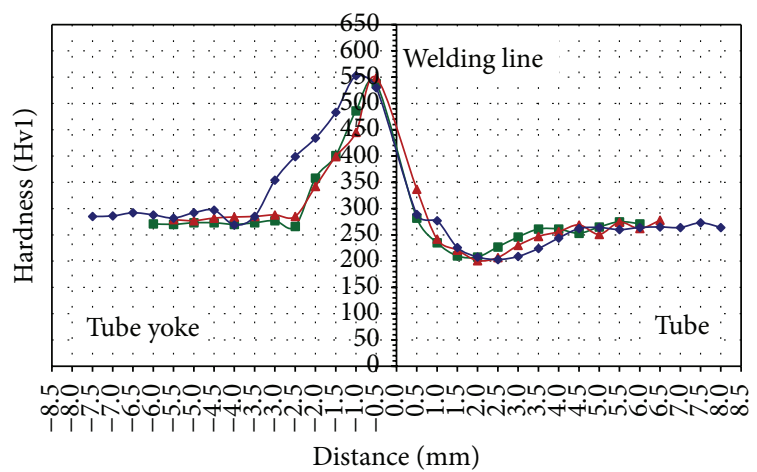

FIGURE 8: Hardness distribution along the welding. removal where required, and reduces the notch effect of the welding flash [22].

After the welding process, a notch is generated between the flash rolls of the joint which is depicted in Figure 6. This notch has a small impact on the mechanical behavior of the joint as it exists at a larger diameter with respect to the outside diameter of the work pieces [22].

HAZ which occurs during friction welding process shows different macro/microstructures and different mechanical properties compared to the base material properties. The major reasons for this difference are the heat generation and heat flow in the joint and the permanent mechanical deformations during process between the faying surfaces of the work pieces.

In order to minimize the negative effect of HAZ on the welding joint, process parameters must be optimized. The heat energy required to generate a permanent bonding should be kept as small as possible, which means a quicker process with high rotational speed and low friction time and friction force and with higher upset force. This may result in a narrow HAZ.

3.2. Microstructural Analysis. The microstructure of the friction welding joints was investigated by using an optical microscope with 20x magnification. It was observed that the width of the heat affected zones on the tube side and on the component side was $2 \mathrm{~mm}$ and $1.5 \mathrm{~mm}$, respectively. As a state of the art, finer grains were detected in each HAZ with respect to the grain sizes observed in the base materials. Temperature increase due to heat generation, high levels of permanent plastic deformations along the welding line due to upset forces, and rapid cooling of the welding zone are the main reasons for observing finer grains in the heat affected zones. This structure also enhances the mechanical strength of the welded joint. The microstructure of the welding zone is shown in Figure 7.

3.3. Hardness Distribution. Hardness distributions of consecutively welded and tested three samples were investigated. Hardness was scanned horizontally starting from the tube side towards the tube yoke. Microhardness testing was carried out according to TS EN ISO 6507-1 with a test load of $1 \mathrm{~N}$. The distance between each indentation was approximately
$0.5 \mathrm{~mm}$. The hardness distribution along the welding zone is given in Figure 8.

Within the examined three samples which were welded by using the same friction welding parameters, the highest hardness value was detected as $553 \mathrm{Hvl}, 1 \mathrm{~mm}$ away from the welding line in the hot forged microalloyed component side. This detected hardness value was approximately two times higher than the base material hardness. On the tube side, the minimum hardness value was detected as $201 \mathrm{Hv} 1$ which was $2 \mathrm{~mm}$ away from the welding line. This value is approximately $23.2 \%$ lower than the base material hardness. The hardness drop on the tube side is considered to be a result of decarburization during the friction welding process. As expected, the hardness distributions of all examined samples were showing similar distribution characteristics which indicate proper parameter selection.

Temperature increase due to heat generation, high levels of permanent plastic deformations along the welding line due to upset forces, and rapid cooling of the welding zone are considered to be the major reasons for hardness increase on the hot forged microalloyed component side.

3.4. Tensile Test Results. Five samples $(25 \mathrm{~mm}$ width $\times 75 \mathrm{~mm}$ length) extracted from the welded parts by using wire EDM technique were tensile tested by using Shimadzu Autograph AG-IS test machine with a capacity of 10 ton. The tensile tests were executed at room temperature with a testing speed of $1 \mathrm{~mm} /$ minute.

The samples from 1 to 4 were fractured from the heat affected zone of welded cold drawn steel tube. Sample 5 fractured from the heat affected zone of hot forged microalloyed steel component (Figure 9). Ductile type fracture zones were detected in all samples' failure areas. No failure or discontinuity was detected in the welding lines of the samples.

For samples 1 to 4 , it was detected that the tensile strength of the friction welded joint is approximately $6 \%$ lower than the base material's (welded cold drawn nonalloyed steel tube) tensile strength. For sample 5, the tensile strength of the welding joint is approximately $13 \%$ lower than the base material's (hot forged microalloyed tube yoke) tensile strength. The results of tensile tests are presented in Figure 10 and all samples showed similar characteristics as expected. 


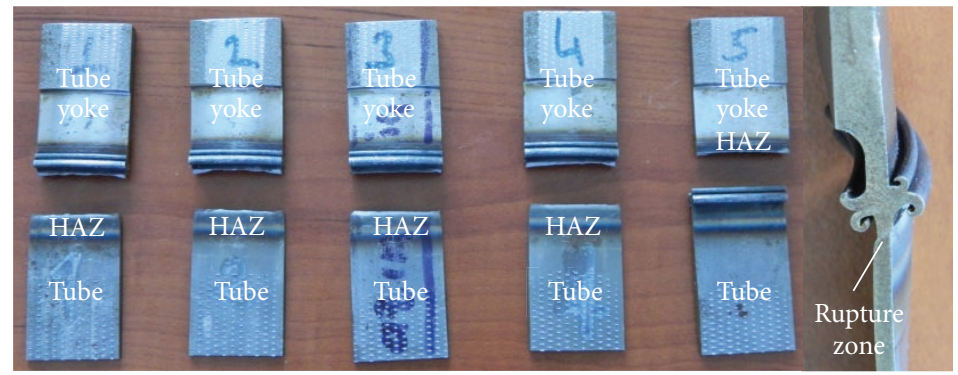

FIgUre 9: Tensile test samples after tensile test.

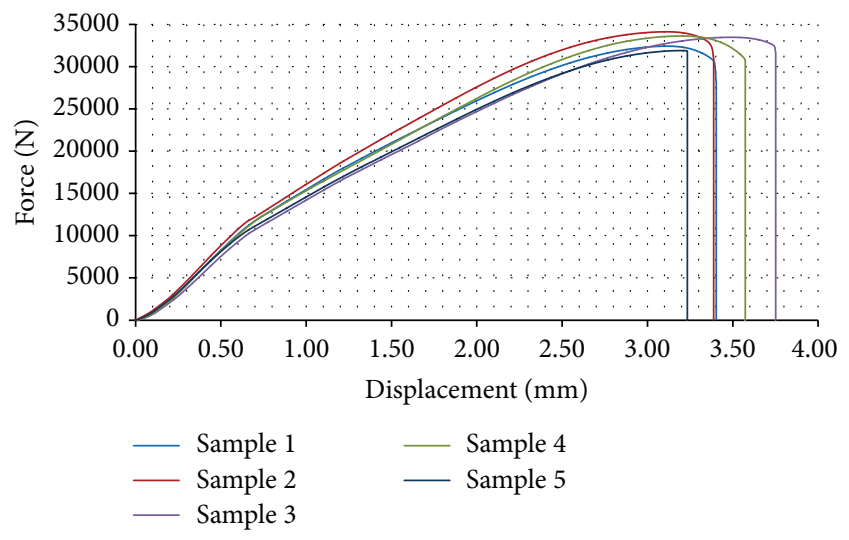

Figure 10: Tensile test results of welded joints.

3.5. Static Torsion Test Results. Six friction welded samples (drive shaft) were subjected to static torsion test in order to determine the torsional load carrying capacity of friction welded joint. In the first step, the welded sample was located and fixed horizontally at $0^{\circ}$ through connection flanges onto the test machine. The welded sample was loaded from one side by activating hydraulic rotary actuator of the test machine. On the other side, the twisting angle was measured by using a torque measuring censor. Each test was conducted until failure of the welded samples. After the tests, no failure was observed on the welded joints but the other components of the drive shafts failed. The results of static torsion tests are presented in Figure 11.

Welded joint areas of all six tested samples without any damage after static torsion tests are shown in Figure 12. Evaluating the test data statistically by Weibull analysis [27], it was detected that the torsional load carrying capacity of friction welded thin walled joint without any damage was $4.252,5 \mathrm{Nm}$ in $95 \%$ confidence interval.

3.6. Torsional Fatigue Test Results. The response of the friction welded joints to several loads likely to occur during the expected lifetime has been studied by several researchers. So far, the fatigue tests have been carried out on the rotating bending fatigue machine $[28,29]$ and the fatigue life distribution property was examined by Morikawa et al. and results were analyzed by Weibull distribution [30].
ReliaSoft Weibull++, www.ReliaSoft.com

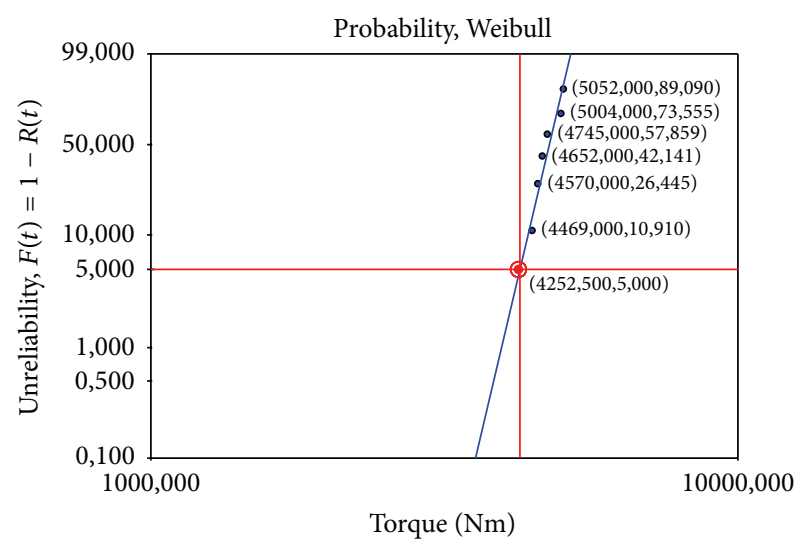

$$
\begin{array}{lll}
\text { Probability } & - & \text { Data points } \\
\text { Data 1 } & - \text { Probability line } \\
\text { 2P-Weibull } & - \text { Target reliability } \\
\text { RRX SRM FM MED } & & \\
F=6 / S=0 &
\end{array}
$$

Beta $=22,580771$, Eta $=4850,310229$, Rho $=0,954464$

FIGURE 11: Weibull analysis of static torsion test results of welded joints.
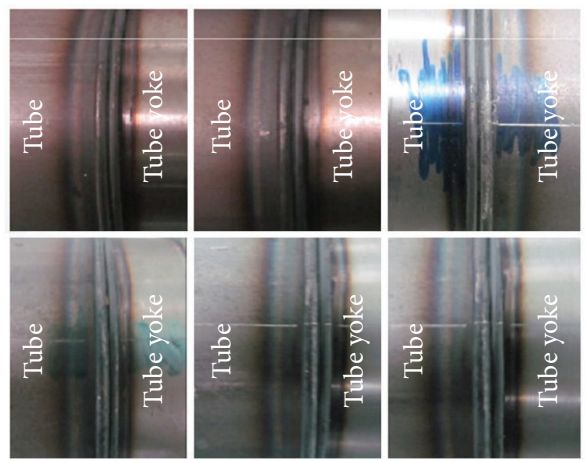

Figure 12: Undamaged welded joint areas after static torsion test.

In this study, six fully reversed $(R=-1)$ torsional fatigue tests were performed to determine the fatigue strength of friction welded joint between the tube yoke and the cold drawn steel tube. All fully reversed torsional fatigue tests 
TABLE 2: Results of fully reversed $(R=-1)$ torsional fatigue tests.

\begin{tabular}{cccc}
\hline & Shear stress amplitude (MPa) & Cycles to failure & Failure location \\
\hline 1 & 72 & 254.897 & HAZ-tube \\
2 & 72 & 307.043 & HAZ-tube \\
3 & 72 & 326.675 & HAZ-tube \\
4 & 72 & 382.393 & HAZ-tube \\
5 & 72 & 341.364 & HAZ-tube \\
6 & 72 & 428.187 & HAZ-tube \\
\hline
\end{tabular}

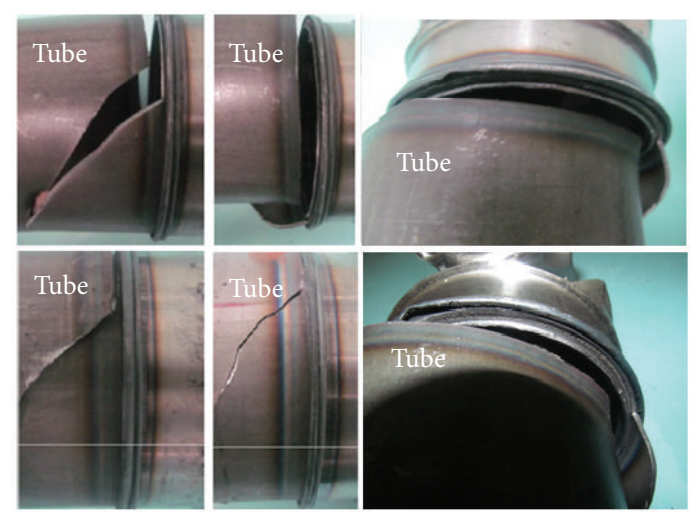

FigURE 13: Fatigue failures of welded joints during fully reversed fatigue tests.

were performed under constant amplitude at a torsional loading level, which were determined depending on field test data of the light commercial vehicle and which will create a maximum shear stress of $72 \mathrm{MPa}$ at the outer surface of the precision welded cold drawn tube. Frequency of the tests was $3 \mathrm{~Hz}$. All tests were conducted until failure of the welded samples. The fully reversed torsional test results are reported in Table 2. It was detected that all tested friction welded joints were damaged from the HAZ of precision welded cold drawn steel tube. The characteristics of fatigue failures detected during fully reversed fatigue tests are shown in Figure 13.

Test results are statistically evaluated by using twoparameter Weibull distributions for fatigue life analysis. ReliaSoft Weibull++ software package [27] was used to identify the relationship between probabilities of failure and fatigue life for given torque amplitude level. The graphical interpretation of fully reversed torsional fatigue test results in 95\% confidence interval is presented in Figure 14. The fatigue life of friction welded joints at given torque amplitude which creates $72 \mathrm{MPa}$ at the outer surface of the precision welded cold drawn tube was detected as $220.066,3$ cycles in $95 \%$ confidence interval.

\section{Conclusions}

In this study, the weldability of thin walled tubular steel structures having different material properties by friction welding technique is experimentally investigated and obtained results are as follows:
ReliaSoft Weibull++, www.ReliaSoft.com

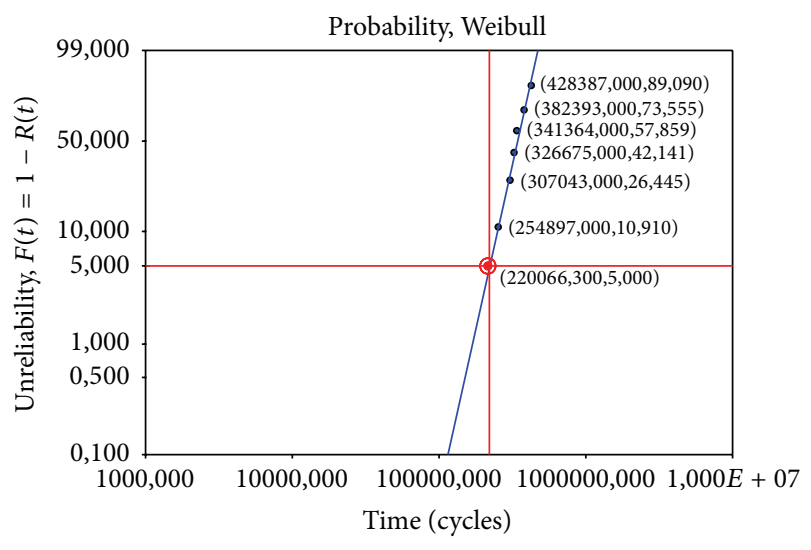

$$
\begin{aligned}
& \text { Probability } \\
& \text { Data } 1 \\
& \text { 2P-Weibull } \\
& \text { RRX SRM FM MED } \\
& F=6 / S=0
\end{aligned}
$$

Beta $=5,977345$, Eta $=364995,450224$, Rho $=0,989867$

Figure 14: Fatigue life of welded joint in 95\% confidence level.

(i) Thin walled hot forged microalloyed tube yokes and cold drawn nonalloyed steel tubes which have a thickness/outside diameter ratio $(t / D)$ of less than 0.1 were successfully welded by using direct drive friction welding method.

(ii) After the microstructural analysis of the welding zone, it was detected that the length of heat affected zones (HAZ) on the tube side and on the tube yoke side was $2 \mathrm{~mm}$ and $1.5 \mathrm{~mm}$, respectively.

(iii) The hardness distribution along the welding zone was investigated and, within the examined three samples, the highest hardness value was detected as $553 \mathrm{Hvl}$ $1 \mathrm{~mm}$ away from the weld line in the hot forged microalloyed tube yoke side.

(iv) Five samples were tested in order to determine the tensile strengths of the friction welded joints. The lowest detected tensile strength of the joints was 13\% less than the base materials' tensile strength.

(v) Six samples were subjected to static torsion test in order to determine the torsional load carrying capacity of the welded joints. It was detected that the torsional load carrying capacity of friction welded thin walled tubular joints without any damage was $4.252,5 \mathrm{Nm}$ with a $95 \%$ confidence interval.

(vi) Six fully reversed torsional fatigue tests were performed to detect the fatigue life of friction welded joints. It was detected that the fatigue life of friction welded joints at a shear stress level of $72 \mathrm{MPa}$ at the outer surface of the precision welded cold drawn tube was $220.066,3$ cycles in $95 \%$ confidence interval. 


\section{Competing Interests}

The authors declare that they have no competing interests.

\section{Acknowledgments}

The authors would like to thank Dokuz Eylül University, Scientific Research Fund, for their financial support through BAP 2012.KB.FEN.112 and Tirsan Kardan A.Ş., Research and Development Center, for giving the opportunity of using testing equipment.

\section{References}

[1] M. Kimura, K. Seo, M. Kusaka, and A. Fuji, "Observation of joining phenomena in friction stage and improving friction welding method," JSME International Journal Series A Solid Mechanics and Material Engineering, vol. 46, no. 3, pp. 384-390, 2003.

[2] M. Kimura, M. Choji, M. Kusaka, K. Seo, and A. Fuji, "Effect of friction welding conditions and aging treatment on mechanical properties of A7075-T6 aluminium alloy friction joints," Science and Technology of Welding and Joining, vol. 10, no. 4, pp. 406412, 2005.

[3] M. Kimura, M. Kusaka, K. Seo, and A. Fuji, "Improving joint properties of friction welded joint of high tensile steel," JSME International Journal, Series A: Solid Mechanics and Material Engineering, vol. 48, no. 4, pp. 399-405, 2006.

[4] M. Sahin, H. E. Akata, and T. Gulmez, "Characterization of mechanical properties in AISI 1040 parts welded by friction welding," Materials Characterization, vol. 58, no. 10, pp. 10331038, 2007.

[5] M. Kimura, Y. Saitoh, M. Kusaka, K. Kaizu, and A. Fuji, "Effect of friction welding condition and weld faying surface properties on tensile strength of friction welded joint between pure titanium and pure copper," Journal of Solid Mechanics and Materials Engineering, vol. 5, no. 12, pp. 849-865, 2011.

[6] M. Kimura, M. Kusaka, K. Kaizu, and A. Fuji, "Effect of friction welding condition on joining phenomena and tensile strength of friction welded joint between pure copper and low carbon steel," Journal of Solid Mechanics and Materials Engineering, vol. 3, no. 2, pp. 187-198, 2009.

[7] S. R. Divagar and M. M. Kumaran, "Joining the different materials using friction welding-a review," International Journal of Mechanical Engineering and Robotics Research, vol. 4, no. 1, pp. 117-122, 2015.

[8] M. Şahin, "Joining with friction welding of high-speed steel and medium-carbon steel," Journal of Materials Processing Technology, vol. 168, no. 2, pp. 202-210, 2005.

[9] N. Özdemir, "Investigation of the mechanical properties of friction-welded joints between AISI 304L and AISI 4340 steel as a function rotational speed," Materials Letters, vol. 59, no. 19-20, pp. 2504-2509, 2005.

[10] V. V. Satyanarayana, G. M. Reddy, and T. Mohandas, "Dissimilar metal friction welding of austenitic-ferritic stainless steels," Journal of Materials Processing Technology, vol. 160, no. 2, pp. 128-137, 2005.

[11] S. Çelik and İ. Ersozlu, "Investigation of the mechanical properties and microstructure of friction welded joints between AISI 4140 and AISI 1050 steels," Materials and Design, vol. 30, no. 4, pp. 970-976, 2009.
[12] I. Mitelea, V. Budau, and C. Craciunescu, "Dissimilar friction welding of induction surface-hardened steels and thermochemically treated steels," Journal of Materials Processing Technology, vol. 212, no. 9, pp. 1892-1899, 2012.

[13] A. Ambroziak, M. Korzeniowski, P. Kustroń, M. Winnicki, P. Sokołowski, and E. Harapińska, "Friction welding of aluminium and aluminium alloys with steel," Advances in Materials Science and Engineering, vol. 2014, Article ID 981653, 15 pages, 2014.

[14] B. J. Eberhard, B. W. Schaaf Jr., and A. D. Wilson, "Friction weld ductility and toughness as influenced by inclusion morphology," Welding Journal, vol. 16, no. 3, pp. 171-178, 1983.

[15] K.-I. Ogawa, H. Nakayama, Y. Ohue, and A. Hasui, "Fatigue strength characteristics of S35C/S35C friction welded tubular butt joints," Journal of the Society of Materials Science, vol. 37, no. 421, pp. 1209-1215, 1988.

[16] M. Kimura, A. Ichihara, M. Kusaka, and K. Kaizu, "Joint properties and their improvement of AISI 310S austenitic stainless steel thin walled circular pipe friction welded joint," Materials and Design, vol. 38, pp. 38-46, 2012.

[17] M. V. Kumar and V. Balasubramanian, "Microstructure and tensile properties of friction welded SUS $304 \mathrm{HCu}$ austenitic stainless steel tubes," International Journal of Pressure Vessels and Piping, vol. 113, pp. 25-31, 2014.

[18] G. Kawai, K. Ogawa, R. Tsujino, and H. Tokisue, "Statistical strength characteristics of aluminum alloy pipe and carbon steel pipe friction weld joints," Journal of Japanese Society of Fracture Strength of Materials, vol. 33, no. 1, pp. 1-10, 1999 (Japanese).

[19] Y. Ohkuba, S. Iwamura, and H. Hatta, "Thermal analysis on friction welding of carbon steel tube and AA5154 aluminum tube," Sumitomo Light Metal Technical Reports, vol. 48, no. 1, pp. 27-32, 2007 (Japanese).

[20] H.-S. Shin, J.-S. Park, and Y. Yokoyama, "Dissimilar friction welding of tubular Zr-based bulk metallic glasses," Journal of Alloys and Compounds, vol. 504, supplement 1, pp. S275-S278, 2010.

[21] M. Kimura, M. Kusaka, K. Kaizu, K. Nakata, and K. Nagatsuka, "Friction welding technique and joint properties of thin-walled pipe friction-welded joint between type 6063 aluminum alloy and AISI 304 austenitic stainless steel," International Journal of Advanced Manufacturing Technology, vol. 82, no. 1, pp. 489-499, 2016.

[22] American Welding Society, "Recommended practices for friction welding," ANSI/AWS C6.1-89, American Welding Society, Miami, Fla, USA, 1989.

[23] M. Kimura, A. Ichihara, M. Kusaka, and K. Kaizu, "Joint properties and their improvement of AISI 310 S austenitic," Materials \& Design, vol. 38, pp. 38-46, 2012.

[24] K. K. Wang, "Friction welding," Welding Research Council Bulletin, vol. 204, pp. 1-21, 1975.

[25] M. Maalekian, "Friction welding_critical assessment of literature," Science and Technology of Welding and Joining, vol. 12, no. 8, pp. 738-759, 2007.

[26] N. S. Kalsi and V. S. Sharma, "A statistical analysis of rotary friction welding of steel with varying carbon in workpieces," The International Journal of Advanced Manufacturing Technology, vol. 57, no. 9-12, pp. 957-967, 2011.

[27] 2016, http://www.reliasoft.com/Weibull/.

[28] J. H. Yan, X. L. Zheng, and K. Zhao, "Prediction of fatigue life and its probability distribution of notched friction welded joints under variable-amplitude loading," International Journal of Fatigue, vol. 22, no. 6, pp. 481-494, 2000. 
[29] H. Masayoshi and K. Ryoma, "Fatigue properties of friction welded joints with flash by austenitic stainless steel and various machine part carbon steels," Welding International, vol. 29, no. 1, pp. 10-17, 2015.

[30] K. Morikawa, Y. Ohue, K. Ogawa, and H. Nakayama, "Fatigue strength characteristics of A6061 aluminum alloy and S35C carbon steel friction welded joints," in Proceedings of the 10th International Offshore and Polar Engineering Conference, J. S. Chung, Ed., vol. 1, pp. 145-149, Seattle, Wash, USA, June 2000.

[31] "Steel tubes for precision applications-technical delivery conditions-part 2: welded cold drawn tubes," Tech. Rep. DIN EN 10305-2: 2010-05, Deutsches Institut für Normung, Berlin, Germany, 2010. 

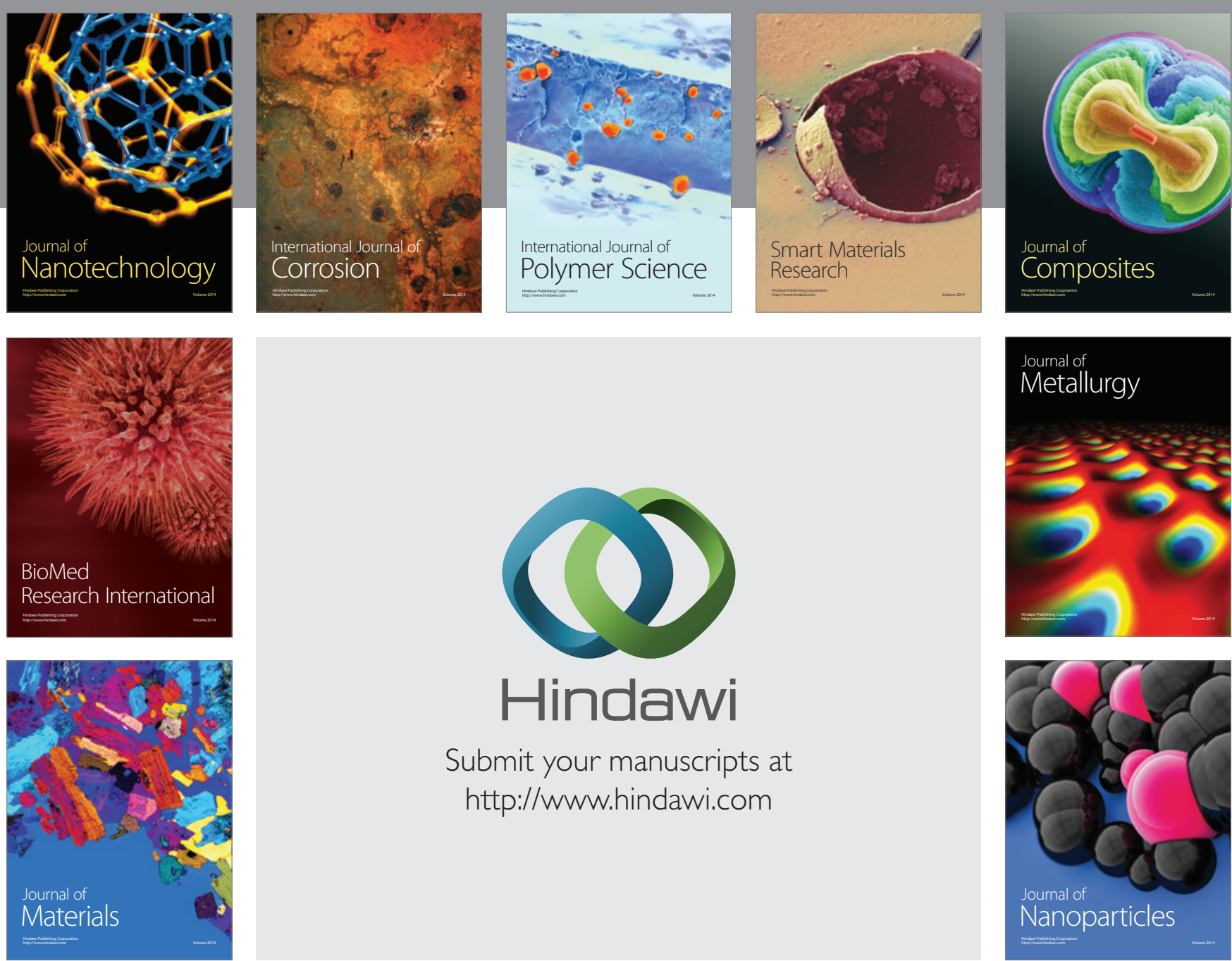

\section{Hindawi}

Submit your manuscripts at

http://www.hindawi.com

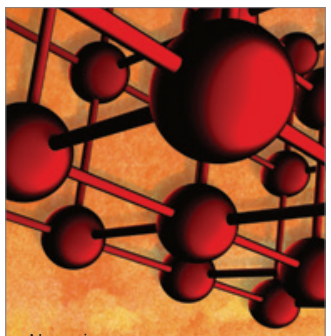

Materials Science and Engineering
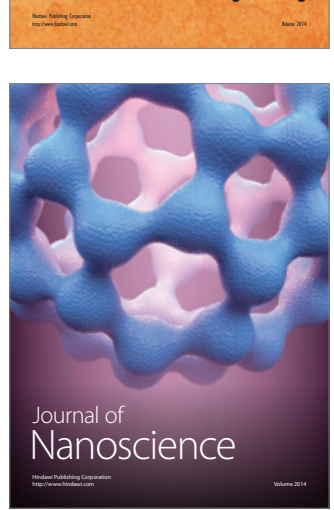
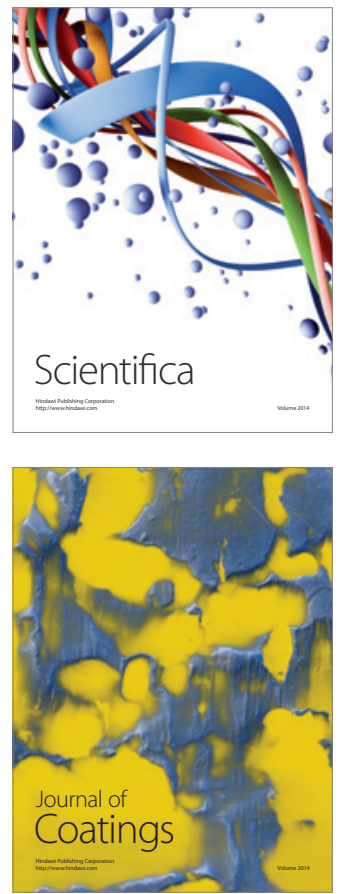
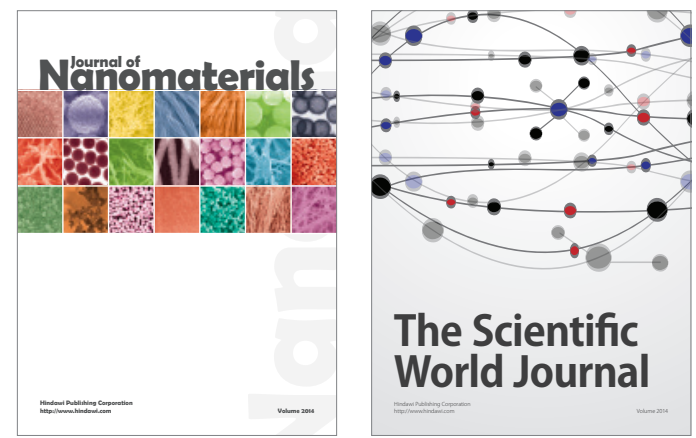

The Scientific World Journal
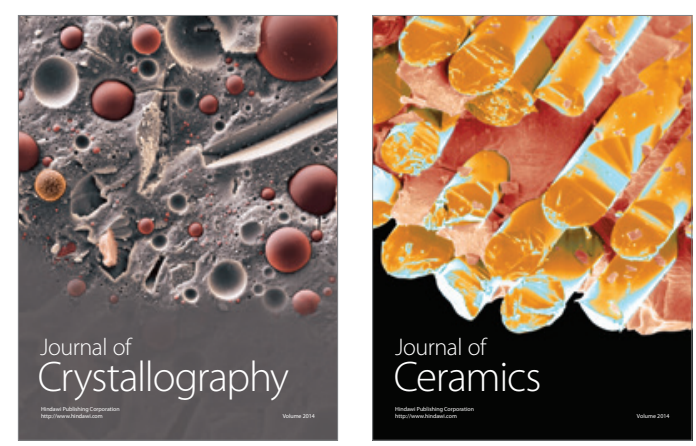
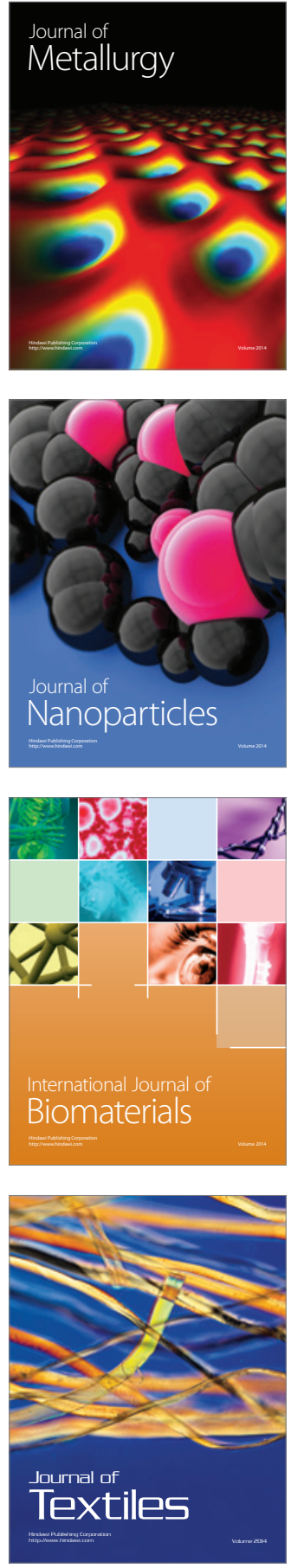